\title{
Web Winding Simulation and Wound Roll Stresses*
}

\author{
Shigeo YANABE**, Kengo TAKAHASHI*** and Toru YAMASHITA*** \\ **Department of Mechanical Engineering, Nagaoka University of Technology \\ 1603-1 Kamitomiokamachi, Nagaoka-city, Niigata, 940-2188, Japan \\ E-mail:yanabe@mech.nagaokaut.ac.jp \\ ${ }^{* * *}$ Graduate course student of School of Mechanical Engineering, \\ Nagaoka University of Technology
}

\begin{abstract}
A method for simulating a web winding process and for predicting wound roll stresses is proposed. The simulation model is two-dimensional and is composed of a web and a core. The simulation was carried out on a FEM software to investigate effects of a slip between web layers, a core rigidity, and a leading edge of a wound web on the wound roll stress distributions. The results show that both the radial and circumferential stresses of the wound roll become extremely larger when the web layer slip is considered. While they decrease when the core rigidity becomes lower. The simulated stresses for no slip cases are compared with the results obtained by Hakiel model.
\end{abstract}

Key words: Finite Element Method, Simulation, Web, Winding, Roll, Stress Distribution, Slip

\section{Introduction}

Recently, a huge amount of webs such as optical films, package films, and papers are produced on a large scale and used in many industrial fields. In order to rise productivity, both a production line speed and a width of web are increasing. However, there are many technical problems on web handling processes like transportation and winding. A skew and wrinkle of a web transported by rollers and several defects like a telescope, starring or concave of wound rolls are typical examples of the web handling problems. Concerning the wound roll defects, they depend strongly on the wound roll stress distributions, which are determined by material properties of a web and core and winding conditions, and many studies have been done to predict the roll stresses.

Altman ${ }^{(1)}$ proposed integration formulas for predicting the radial and circumferential stresses of a wound roll considering that the wound roll is a thick-walled cylinder with boundary conditions of radial stresses on a core and the roll outer radius and both Young's moduli and Poisson's rations of the roll in the radial and circumferential directions are constant and have an orthotropic nature.

Hakiel ${ }^{(3)}$ proposed a new iteration method for calculating the radial and circumferential stresses of the wound roll. In his model, the roll is assumed to be a collection of concentric hoops of web and a winding process is modeled as adding a tensioned hoop onto the roll one by one, neglecting a slip between web layers. The roll elasticity has orthotropic and non-linear properties and the roll stress distributions are a function of the roll radius only.

Good et al. ${ }^{(4)}$ noticed that the radial stress of a wound roll fell far short of the Hakiel's model results and they considered that the web tension became smaller due to the decrease in the web caliper during winding. They proposed an improved Hakiel calculation model and show that the predicted results had a good agreement with the experimental results

${ }^{*}$ Received 24 July, 2009 (No. 09-0370) [DOI: 10.1299/jamdsm.4.281]

Copyright $@ 2010$ by JSME 
when the slip between web layers is negligible.

After that, Hakiel ${ }^{(5)}$ and Kedl ${ }^{(6)}$ tried to extend the one-dimensional Hakiel calculation model to a two-dimensional model, which includes the web-width direction. The wound roll is divided into several segments (strips) over the width direction. In each segment, the radial and circumferential stresses are constant in the width direction and can be calculated by the ordinary Hakiel model.

Wickert et al. ${ }^{(7),(8)}$ treated a two-dimensional axi-symmetrical finite element model and constructed an algorithm to calculate increments of radial, circumferential, and axial stresses of a roll when a new n-th lap of web was wrapped. They showed the predicted distributions of the above three stress components on a radial-width plane. However, the shape of the radial and circumferential stress distributions along the radial direction seem to be different from those obtained by the ordinary Hakiel model.

While, Tanimoto et al. ${ }^{(10)}$ extended the Hakiel model to taking account of both air-entrainment during winding and air-permeability of web layers. They show that the radial stress of the wound roll decreases by the air-entrainment because of the decrease in an equivalent radial stiffness of the wound roll but the air-permeability recovers the equivalent radial stiffness and the radial stress.

These studies give us useful information but the wound roll defects have not been clarified yet. It is desirable to develop a new method for predicting the roll stresses under more real situations, considering effects of the slip between web layers, a flexible core, and a leading edge of a wound web and extension to a three-dimensional model.

One of the authors ${ }^{(1)}$ has simulated a generation process of a folded wrinkle of a tensioned web transferred by a tilt roller by using a FEM software. In this simulation, a driving roller is rotated step by step with a constant small angle and both displacements and stresses of the web are statically calculated at each step. A motion simulation of the folded wrinkle generation process is obtained as a sequence of the simulated results of more than thousands of steps. The results show that a wavy wrinkle runs onto the tilt roller and the wrinkle width becomes smaller with increasing its height due to a difference of web skew velocity along the web width direction, and finally it falls down on the roller and a folded wrinkle generates. This type of the folded wrinkle tends to occur as the roller tilt or the friction coefficient becomes larger or as the web tension becomes smaller.

In the present study, a web winding process is simulated by applying the above mentioned motion simulation. A FEM model is two-dimensional and is composed of a web and a core. The radial and circumferential stress distributions of wound rolls are obtained for several cases. The results show effects of a web layer slip, a flexible core and a starting point of web winding on the stress distributions. Some of the results are compared with those obtained by the Hakiel model.

\section{Simulation model and Procedure}

A web winding process was simulated by using a FEM software Marc 2005 r3. Figure 1 shows a simulation model treated here. The model is two-dimensional and is composed of a core with $20 \mathrm{~mm}$ in radius $\left(\mathrm{r}_{\mathrm{c}}\right)$ and a web with 6 or $20 \mathrm{~m}$ in length $(\mathrm{L}), 1 \mathrm{~m}$ in width (an imaginary width) and $0.5 \mathrm{~mm}$ in thickness $(\mathrm{h})$. The web is divided by quadrilateral plane strain elements with $2 \mathrm{~mm}$ in length and $0.5 \mathrm{~mm}$ in height. Young's modulus and Poisson's ratio for an isotropic web are $\mathrm{E}_{\theta}=\mathrm{E}_{\mathrm{r}}=50 \mathrm{Mpa}$ and $v=0.01$ and the winding tension is $240 \mathrm{~N} / \mathrm{m}\left(=\mathrm{T}_{\mathrm{w}}\right)$ (see Table 1$)$. The tension is constant throughout the winding. A radius of wound roll is 36 or $60 \mathrm{~mm}\left(\mathrm{r}_{\mathrm{s}}\right)$. For an orthotropic web, material properties (input data for Marc) shown in Table 2 are used $\left(\mathrm{E}_{\theta}=\mathrm{E}_{11}=50 \mathrm{Mpa}, \mathrm{E}_{\mathrm{r}}=\mathrm{E}_{22}=5 \mathrm{Mpa}\right)$. The core is rigid in most cases and is modeled as a rigid circular surface but in one case, it is assumed to be flexible and is divided by the same type of element as the web is divided.

The simulation procedure is as follows. (1)The core and web are made on a pre-post display. The web is moved to the core and the leading edge of the web is fixed (glued) to the 
core surface. (2)The winding tension is applied to the end edge of the web. (3)The core is rotated at a constant angular velocity. The web is wound around the core as the core rotates by a constant angle at each calculation step $(0.01 \mathrm{rad} / \mathrm{step})$. The displacement, stress, slip, friction force, and other quantities are calculated at each step by a static analysis and a motion simulation is obtained as a series of the calculated result of each step. So many calculation steps are needed to get a relatively thick wound roll. Then only the calculation data at every 100 steps are stored and used to show the results. Five cases shown in Table 3 are simulated, considering whether the web elasticity is isotropic or orthotropic, the slip between web layers is considered or not and finally the core is rigid or flexible. The friction force acting between web layers is assumed to be a function of a friction coefficient $\mu$, a normal force $\mathrm{P}$, and a slip velocity $\mathrm{V}_{\mathrm{r}}$ and $\mathrm{C}$ is a reference slip velocity (see Eq.(1) and Fig.2). It should be determined by experiments but in this simulation $\mu=1$ and $\mathrm{C}=1 \mathrm{~mm} / \mathrm{s}$ are assumed. A total calculation steps for the Case A $\left(80^{\text {th }}\right.$ lap) is about 50,000 and the calculation time is about 200 hours in our computer center machine (SGI- altix4700, CPU:Itanium2, 1.6GHz $\times 64$, 409.6GFLOPS).

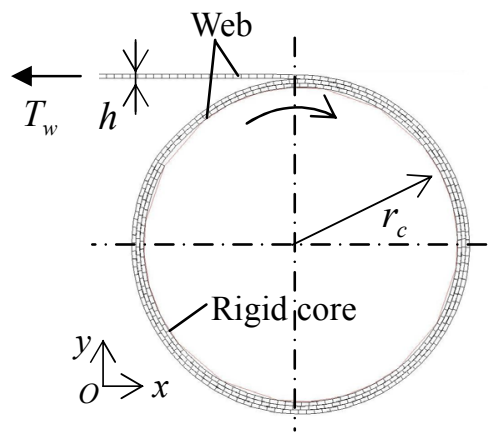

Fig. 1 Two dimensional FEM model for web winding simulation

Table 2 Orthotropic web properties

\begin{tabular}{|l|l|l|}
\hline $\begin{array}{l}\text { Young's } \\
\text { moduli } \\
{[\mathrm{MPa}]}\end{array}$ & $\begin{array}{l}\text { Poisson's } \\
\text { ratios }\end{array}$ & $\begin{array}{l}\text { Shear } \\
\text { moduli } \\
{[\mathrm{MPa}]}\end{array}$ \\
\hline $\mathrm{E}_{11}=50$ & $v_{12}=0.01$ & $\mathrm{G}_{12}=2.48$ \\
\hline $\mathrm{E}_{22}=5$ & $v_{23}=0$ & $\mathrm{G}_{23}=0$ \\
\hline $\mathrm{E}_{33}=50$ & $v_{31}=0$ & $\mathrm{G}_{31}=0$ \\
\hline
\end{tabular}

Table 1 Main parameter values

\begin{tabular}{|l|l|}
\hline$h$ & $0.5 \mathrm{~mm}$ \\
\hline$L$ & $6 / 20 \mathrm{~m}$ \\
\hline$r_{c}$ & $20 \mathrm{~mm}$ \\
\hline$r_{s}$ & $36 / 60 \mathrm{~mm}$ \\
\hline$E_{\theta}$ & $50 \mathrm{MPa}$ \\
\hline$E_{r}$ & $5 \mathrm{MPa}$ \\
\hline$v$ & 0.01 \\
\hline$T_{w}$ & $240 \mathrm{~N} / \mathrm{m}$ \\
\hline
\end{tabular}

Table 3 Simulation cases

\begin{tabular}{|c|l|l|l|}
\hline Case & Web elasticity & $\begin{array}{l}\text { Slip between } \\
\text { layers }\end{array}$ & $\begin{array}{l}\text { Core } \\
\text { elasticity }\end{array}$ \\
\hline \hline A & isotropic & no slip (glue) & rigid \\
\hline B & orthotropic & no slip (glue) & rigid \\
\hline C & isotropic & slip $(\mu=1)$ & rigid \\
\hline D & orthotropic & slip $(\mu=1)$ & rigid \\
\hline \hline E & orthotropic & no slip(glue) & flexible \\
\hline
\end{tabular}

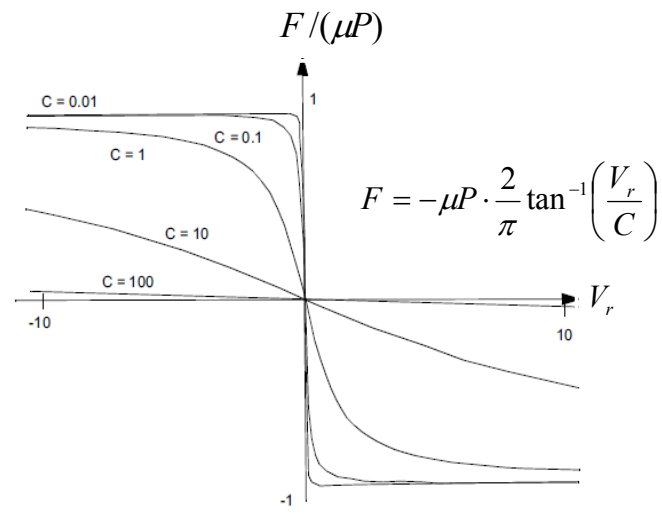

Fig.2 Friction force $C=1 \mathrm{~mm} / \mathrm{s}$ 


\section{Simulation results}

Figure 3 shows a wound roll obtained by the FEM motion simulation. The radial and circumferential stresses of the wound roll are obtained from the simulation results of $\sigma_{22}$ $\left(=\sigma_{r}\right)$ and $\sigma_{11}\left(=\sigma_{\theta}\right)$ at each nodal point. In the following figures, the average of the stresses of the inner and outer nodes of the web element is plotted. The stress data $\sigma_{i i}(\mathrm{i}=1,2)$ are mainly collected along a reference radial line but in some cases along a circumferential line shown in Fig.3.

\section{1 $\sigma_{r}(r)$ and $\sigma_{\theta}(r)$ for no slip cases}

Figures 4(a) and (b) show the simulation results of the roll stresses at the $80^{\text {th }}$ lap of winding for the Case A (no-slip, isotropic case). The horizontal axis is a non-dimensional roll radius and the vertical is $\sigma_{r}(r)$ and $\sigma_{\theta}(r)$, respectively. In each figure, the dot points denote the simulation results and the solid line is the result predicted by the Hakiel model. Both results show the same tendency but the simulation results are a little bit larger than the Hakiel model results. The difference seems to arise from that in the Hakiel model, the strain compatibility equation is derived by neglecting a circumferential displacement of an element. $\sigma_{r}$ and $\sigma_{\theta}$ are proportional to the winding tension $\mathrm{T}_{\mathrm{w}}$ for the Hakiel model results but they are not proportional for the simulation results.

Figures 5(a) and (b) show the simulation results for the Case B (orthotropic, no-slip case). These figures show that the simulation results and the Hakiel model results show nearly the same tendency, especially, in the negative area of $\sigma_{\theta}$.
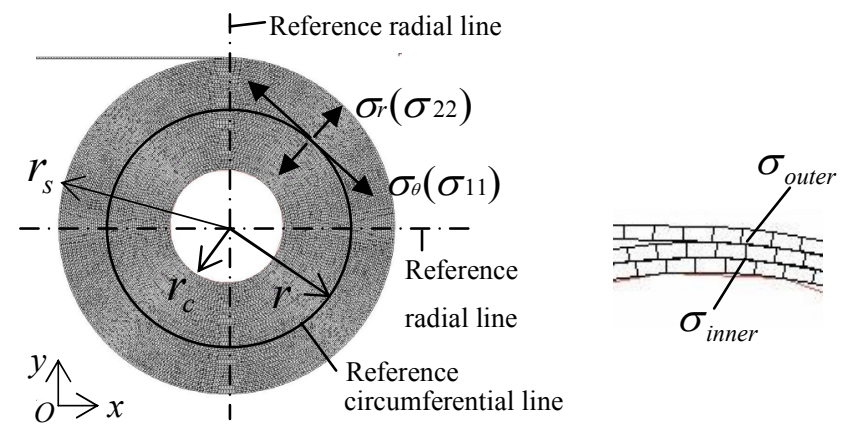

Fig. 3 Wound roll and stresses of a node (a simulation result at the $80^{\text {th }}$ lap of winding)

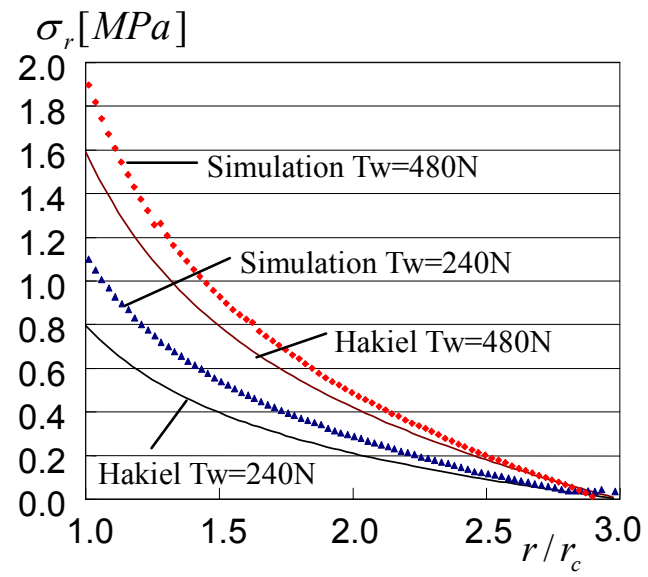

(a) $\sigma_{r}$

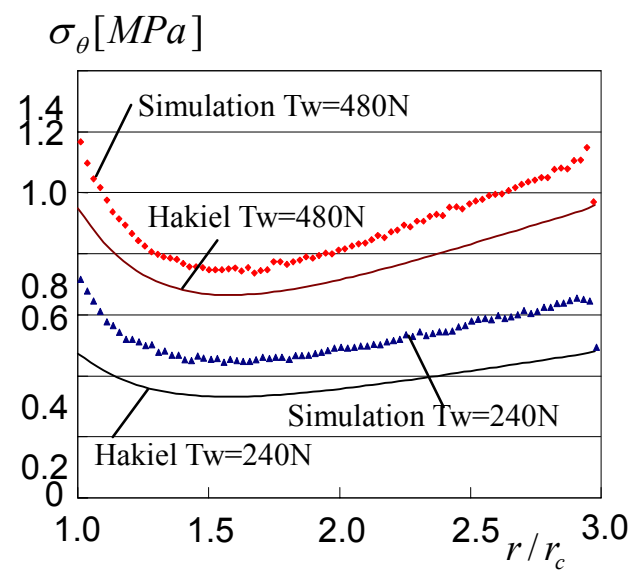

(b) $\sigma_{\theta}$

Fig.4 Simulation results of roll stresses compared with Hakiel model results (at the 80th lap, Case A : isotropic, no-slip) 


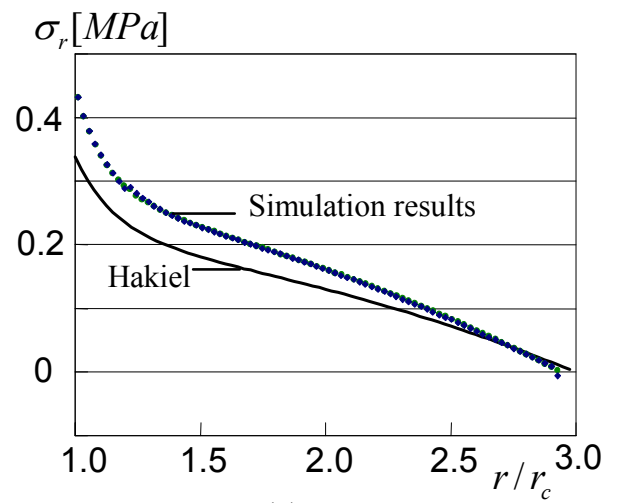

(a) $\sigma_{r}$

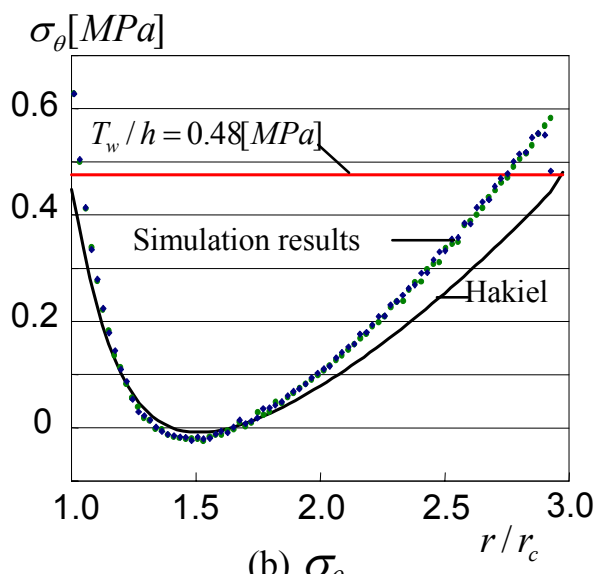

(b) $\sigma_{\theta}$

Fig.5 Simulation results of the roll stresses compared with Hakiel results (at the 80th lap, Case B : orthotropic, no-slip)

\section{$3.2 \sigma_{r}(r)$ and $\sigma_{\theta}(r)$ for slip cases}

Figures 6(a) and (b) show effects of the slip between web layers. The simulated slip cases $\mathrm{C}$ and $\mathrm{D}$ are shown together with the previous no-slip cases A and B. The horizontal and vertical axes are the same as the previous figures. These results show that the roll stresses $\sigma_{r}$ and $\sigma_{\theta}$ become larger when the slip is considered. This is because the web is tightly wrapped due to the slip. In Fig.(b), the $\sigma_{\theta}$ values fluctuate largely in the inner side of the roll. This is because the layer slip does not occur uniformly in the roll.

Figures 7(a) and (b) show the slip between web layers during winding. Figure (a) is at the $5^{\text {th }}$ lap of winding, and Fig.(b) is at the $80^{\text {th }}$ lap of winding. In Fig.(a), five nodes A to E on the successive web layers are close together, but in Fig.(b), they are apart from each other. This means the web layers slip each other during winding. This slip phenomenon is not considered in the Hakiel model.

Figures 8(a) and (b) show change processes of $\sigma_{r}$ and $\sigma_{\theta}$ of four different nodes a-d (whose angular positions are apart from about $90^{\circ}$ ) of the $5^{t^{t}}$ lap layer in Case C. The nod $\mathrm{d}$ is situated on a radial line passing through a gap area between the core and web which is situated just before the leading edge of the wound web. In Fig.(a), the $\sigma_{r}$ of the

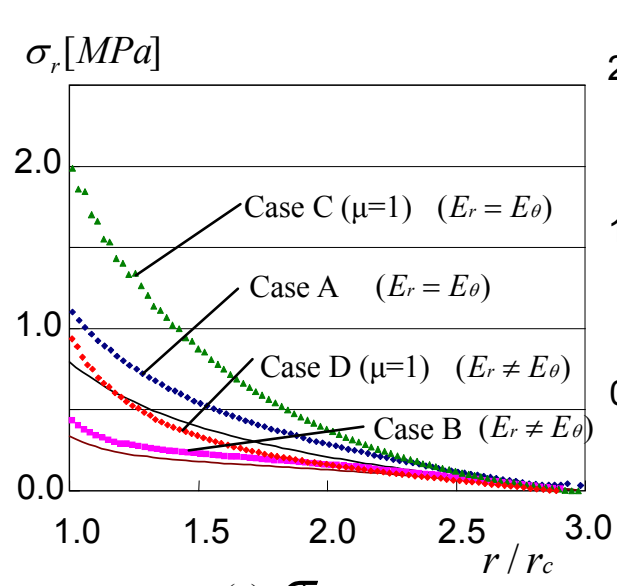

(a) $\sigma_{r}$

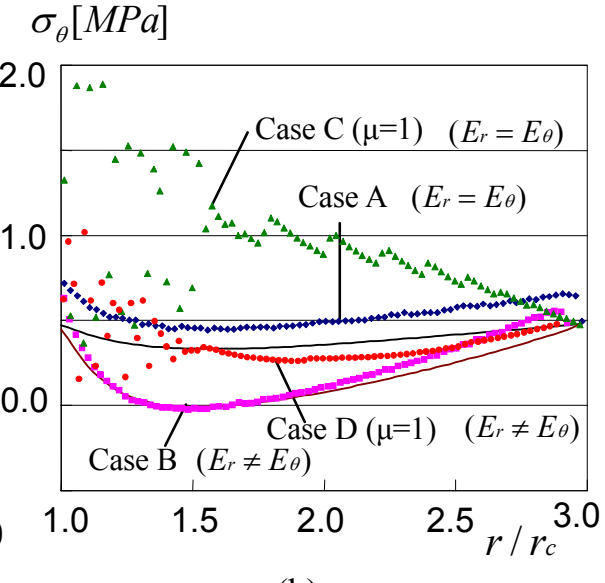

(b) $\sigma_{\theta}$

Fig.6 Stress distributions along radial direction

(Effects of the slip between web layers and orthotropic web elasticity) 
a-c nodes increases gradually as the winding proceeds, but the $\sigma_{r}$ of the d node is almost zero until 40,000 steps and then suddenly increases and decreases. The reason is that the $\sigma_{r}$ of nodes on the inside web layers is zero above the gap area but the $\sigma_{r}$ of the nodes increases when the nodes moves onto the leading part of the wound web due to the layer slip and it decreases when the nodes pass through the leading part. In Fig.(b), the $\sigma_{\theta}$ of the a-d nodes repeats increasing and decreasing violently and makes its amplitude larger as the winding proceeds. It is thought that web elements in the inner roll repeat expansion and contraction gradually due to the web layer slip.

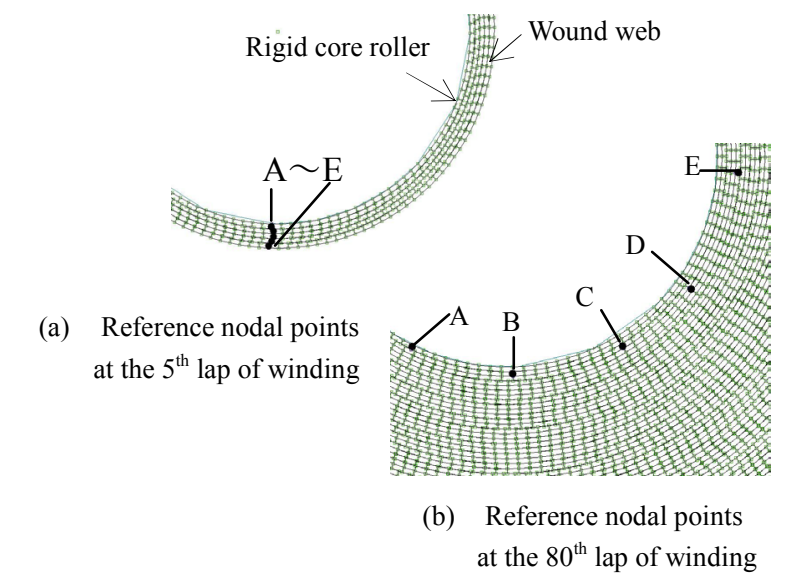

Fig. 7 Slip between web layers during winding

( Case C: isotropic, slip )

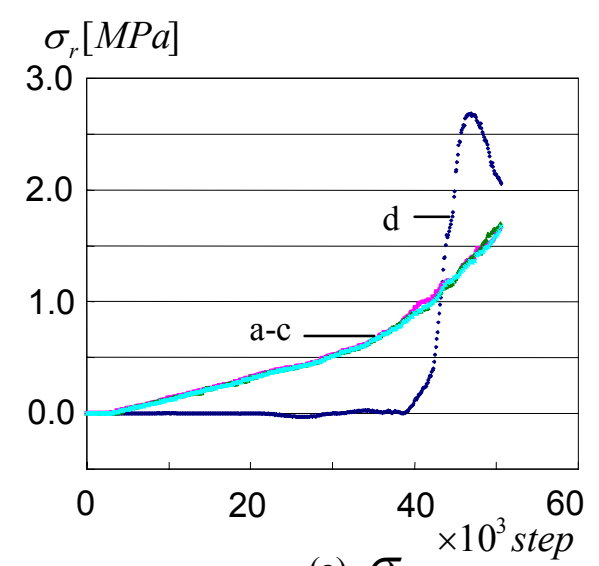

(a) $\sigma_{r}$

\section{$\sigma_{\theta}[\mathrm{MPa}]$}

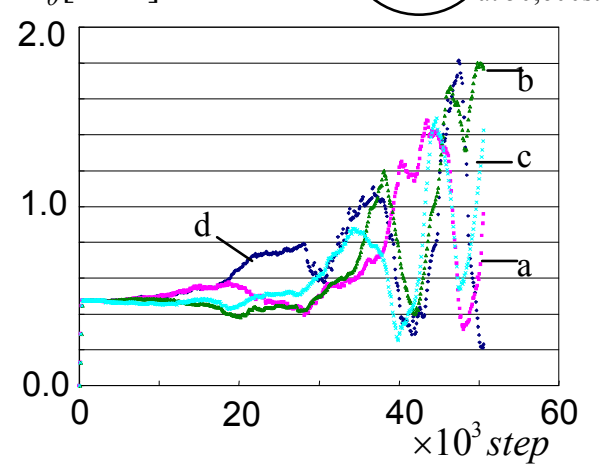

(b) $\sigma_{\theta}$

Fig. 8 Stress changing process of four nodes due to web layer slip during winding ( Case C: isotropic, slip, four nodes on the $5^{\text {th }}$ lap of wound web)

\section{3 $\sigma_{r}(\theta)$ and $\sigma_{\theta}(\theta)$ for no slip and slip cases}

Here we investigated the roll stress distributions along the circumferential direction $\sigma_{r}(\theta)$ and $\sigma_{\theta}(\theta)$. In the Hakiel model, $\sigma_{r}(\theta)$ and $\sigma_{\theta}(\theta)$ are constant because of an assumption but in this simulation there may exist some effect of the starting point P1 (the leading edge) of web winding. The angular position $\theta$ along the circumferential direction is defined as shown in Fig.9. Here the angular position of the point $\mathrm{P} 1$ is $\theta \approx 8.3^{\circ}$.

Figures 10(a) and (b) show variations of $\sigma_{r}(\theta)$ and $\sigma_{\theta}(\theta)$ of the $5^{\text {th }}, 20^{\text {th }}$, and $40^{\text {th }}$ lap layers for the case A (no slip case). In Fig.(a), the $\sigma_{r}(\theta)$ increases and decreases near the $\mathrm{P} 1$ point which is indicated by a vertical line, but in other $\theta$ area, the $\sigma_{r}$ is almost constant. The maximum value of the $\sigma_{r}$ is about 1.4 times larger than the average of $\sigma_{r}(\theta)$ for the $5^{\text {th }}$ lap layer. This change of $\sigma_{r}$ can be observed at the $40^{\text {th }}$ lap layer. It is concluded 
that the starting point of the web winding affects largely the radial stress of the layer elements above or near-off the starting point P1. While in Fig(b), the $\sigma_{\theta}(\theta)$ of the $5^{\text {th }}$ lap layer shows a concave nature before the P1 point but its effect can not be seen for other cases of the $20^{\text {th }}$ and $40^{\text {th }}$ lap of layers.

Figures 11(a) and (b) show variations of $\sigma_{r}(\theta)$ and $\sigma_{\theta}(\theta)$ for the Case C (slip case). In Fig.(a), the $\sigma_{r}(\theta)$ shows the same tendency as shown in Fig.10(a). But in Fig.11(b), $\sigma_{\theta}(\theta)$ changes largely, especially for the $5^{\text {th }}$ lap layer. This variation of $\sigma_{\theta}(\theta)$ is coming from the slip between web layers and it corresponds to the $\sigma_{\theta}(r)$ variation in Figs. 6(b) and $8(b)$.

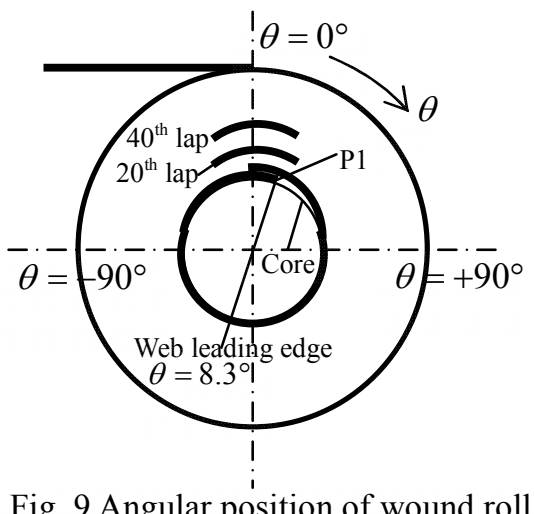

(at the $80^{\text {th }}$ lap, 50,600 step)

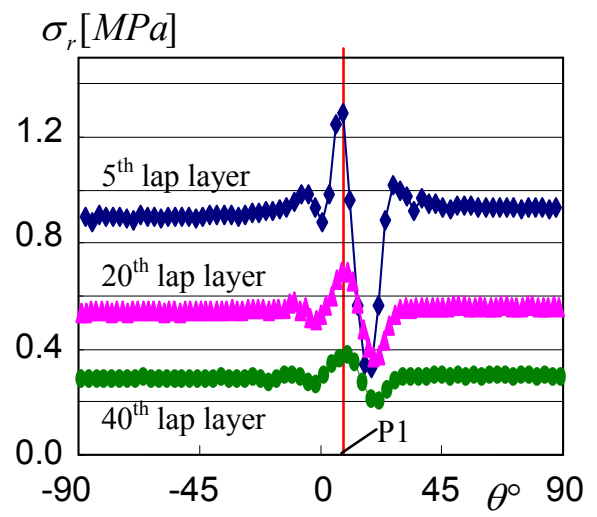

(a) $\sigma_{r}$

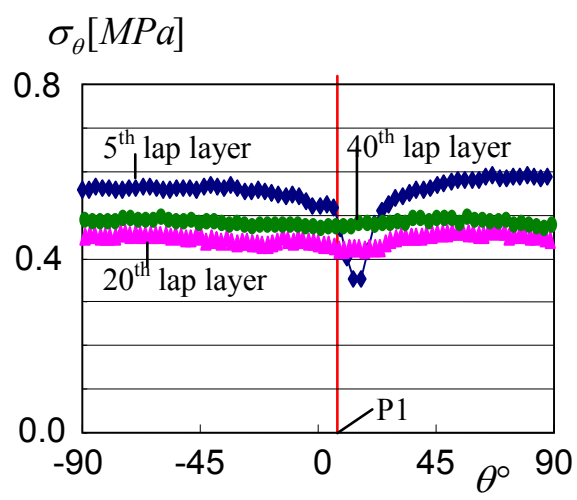

(b) $\sigma_{\theta}$

Fig. 10 Stress distributions along circumferential direction

(Effects of web leading edge, at the $80^{\text {th }}$ lap, Case A: isotropic, no-slip)

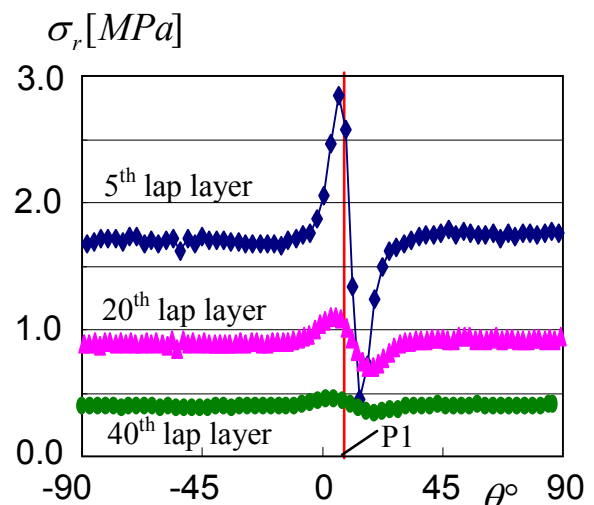

(a) $\sigma_{r}$

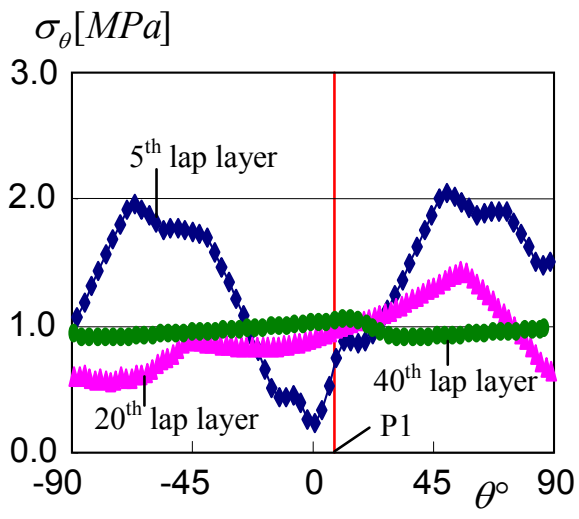

(b) $\sigma_{\theta}$

Fig. 11 Stress distributions along circumferential direction (Effects of web leading edge, at the $80^{\text {th }}$ lap, Case C: isotropic, slip) 


\subsection{Effects of flexible core}

Figure 12 shows a web $(\mathrm{L}=6 \mathrm{~m})$ wound on a flexible core $\left(\mathrm{r}_{\mathrm{c}}=20 \mathrm{~mm}, \mathrm{~h}_{\mathrm{c}}=5 \mathrm{~mm}\right.$, $\mathrm{E}_{\mathrm{c}}=1 \mathrm{MPa}$ ). The inside of the core is glued to a rigid circular surface. The web dimensions, web material properties and other conditions are the same as the case B. Using this model, effects of the flexible core on the wound roll stress distributions are investigated. Figure 13 shows a simulation result where the $33^{\text {rd }}$ lap of the web is wrapped and a distribution of $\sigma_{r}$ is represented in contour. The figure indicates that the leading part of the web sinks in the flexible core and a few areas with high compression and high tension exist.

Figures 14(a) and (b) show the effects of the flexible core on the roll (the web and core) stress distributions along the radial direction. Three curves denote the simulation results for three different core Young's moduli, $\mathrm{Ec}=\infty$ (the rigid core), $\mathrm{Ec}=5$ and $1 \mathrm{MPa}$. The two figures (a) and (b) show that the roll stresses decrease as the flexible core becomes flexible, especially in the $\sigma_{r}$ of the core outer surface and the $\sigma_{\theta}$ of the web inner and the core outer surfaces.

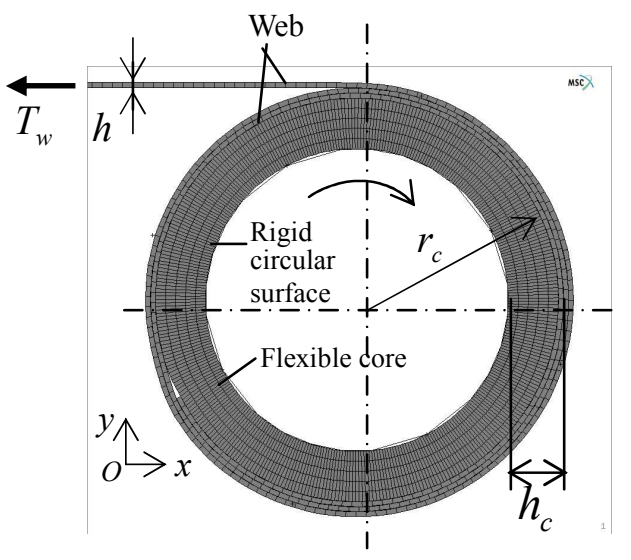

Fig. 12 Web winding model with flexible core (Case E)

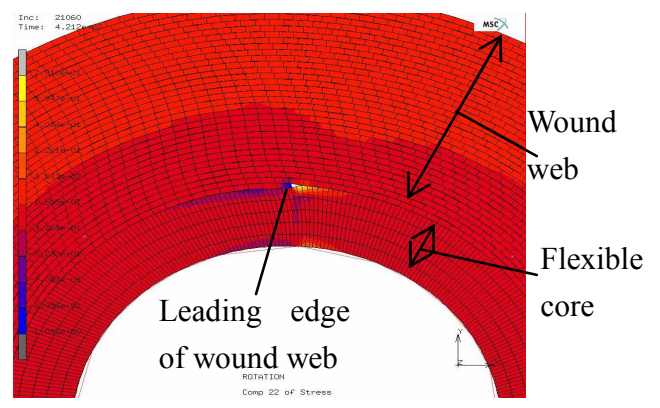

Fig.13 Simulation result in case of flexible core

Distribution of $\sigma_{r}$

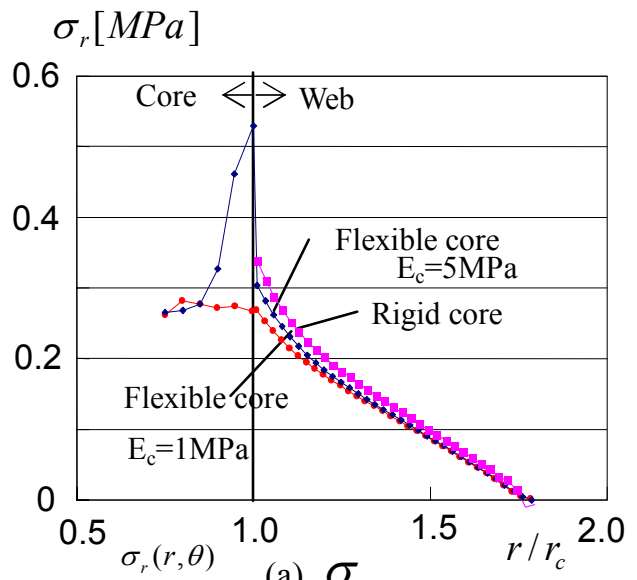

(a) $\sigma$

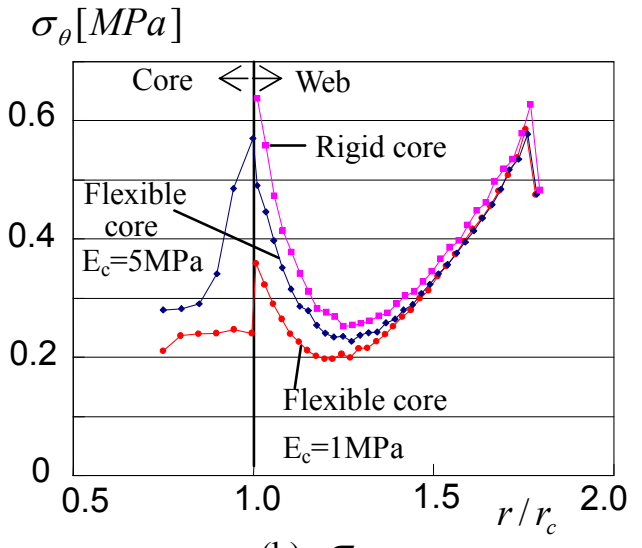

(b) $\sigma_{\theta}$

Fig.14 Effects of flexible core on roll stresses (at the 33rd lap, Case E)

\section{Conclusions}

(1) A two-dimensional web winding simulation method was constructed by the aid of a FEM software and the wound web stress distributions $\sigma_{r}(r, \theta)$ and $\sigma_{\theta}(r, \theta)$ were 
obtained for several cases.

For the cases of neglecting the web layer slip:

(2) The simulated $\sigma_{r}(r)$ and $\sigma_{\theta}(r)$ in the most area of the angular position of the wound roll except near the wind starting angular position show nearly the same tendency as the results calculated by Hakiel model. These simulated $\sigma_{r}(r)$ and $\sigma_{\theta}(r)$ are a little bit (up to 30\%) larger than the Hakiel model results. The reason seems to be that a circumferential displacement is neglected for deriving the strain compatibility equation in the Hakiel model.

(3) The simulated $\sigma_{r}(\theta)$ extremely increases and then decreases near the wind starting angular position. In this simulation, $\sigma_{r}(\theta)$ becomes $20-30 \%$ larger and smaller for its average level, and its effect reaches $40^{\text {th }}$ lap of winding when the $80^{\text {th }}$ lap is wound.

For the cases of considering the web layer slip :

(4) The slip between web layers occurs largely in the inner area of the wound roll. It makes $\sigma_{r}(r)$ and $\sigma_{\theta}(r)$ higher comparing with the cases of neglecting the web layer slip and $\sigma_{\theta}(\theta)$ fluctuates largely in the slip area.

Effects of the flexible core:

(5) The flexible core makes the $\sigma_{r}(r)$ and $\sigma_{\theta}(r)$ lower, especially near the interface between the web and core. The leading part of the wound web sinks into the flexible core and it affects the core and web stress distributions.

\section{Acknowledgements}

The authors wish to thank Koji Hara, a student of graduate school of Nagaoka University of Technology for his first trial of a web winding simulation.

\section{References}

(1) Altman, H. C., Formulas for Computing the Stresses in Center-Wound Rolls, Tappi Journal, Vol. 51, No.4 (1968), pp. 176-1793.

(2) Pfeiffer, J.D., Prediction of roll defects from roll structure formulas, Tappi Journal, Vol. 62, No.10 (1979), pp. 83-85.

(3) Hakiel, Z., Nonlinear model for wound roll stresses, Tappi Journal, Vol. 70 (1987), pp. 113-117.

(4) Good, J.K., Pfeiffer, J.D. and Giachetto, R.M., Losses in Wound-on Tension in the Centerwinding of Wound Rolls, AMD-Vol.149, Web Handling, ASME (1992), pp.1-12.

(5) Hakiel, Z., On the Effect of Width Direction Thickness Variations in Wound Roll, Second International Conference on Web Handling, Oklahoma State University, (1992), pp.79-98.

(6) Kedl, D.M., Using a Two Dimensional Winding Model to Predict Wound Roll Stresses That Occur due to Circumferential Steps in Core Diameter or to Cross-Web Calipar Variation, Second International Conference on Web Handling, Oklahoma State University, (1992), pp.99-112.

(7) Lee, Y. M. and Wickert, J.A., Stress Field in Finite Width Axisymmetric Wound Rolls, Trans.ASME, J. Appl. Mech., Vol. 69 (2002), pp. 130-138.

(8) Lin, P. M. and Wickert, J.A., Analysis of Core Buckling Defects in Sheet Metal Coil Processing, Trans.ASME, J. Manufacturing Science and Engineering., Vol. 125 (2003), pp. 771-777.

(9) Lin, P. M. and Wickert, J.A., Corrugation and Buckling Defects in Wound Rolls, Trans.ASME, J. Manufacturing Science and Engineering., Vol. 128 (2006), pp. 56-64.

(10) Tanimoto, K., Kohno, K., Takahashi, S., Sasaki,M., and Yoshida, F., Numerical Stress Analysis of Wound Roll with Air-Entrainment, Trans. JSME, Ser. A, Vol.68, No.665(2002), pp.161-168. (in Japanese)

(11) Yanabe, S. and Inomata, K., Simulation on Skew and Folded Wrinkle of Film Transferred by Misaligned Roller, Trans. JSME, Ser. C, Vol.73, No.732(2007), pp.2343-2349. (in Japanese)

(12) Hashimoto, T. and Kiribe, S., Optimization of Winding Tension for Preventing Wrinkle and Slippage in Wound Roll of Films, Tribologist, Vol.52, No.7(2007), pp.533-545. (in Japanese) 